Editor's Note: These short reviews of recent JNeurosci articles, written exclusively by students or postdoctoral fellows, summarize the important findings of the paper and provide additional insight and commentary. If the authors of the highlighted article have written a response to the Journal Club, the response can be found by viewing the Journal Club at www.jneurosci.org. For more information on the format, review process, and purpose of Journal Club articles, please see http://jneurosci.org/content/ preparing-manuscript\#journalclub.

\title{
Elucidating the Role of the Ventrolateral Prefrontal Cortex in Economic Decision-Making
}

\author{
Travis A. Wearne \\ School of Psychology, University of New South Wales, Kensington, New South Wales 2052, Australia \\ Review of Chung et al.
}

The ability to make autonomous, reasoned, and informed decisions concerning economic matters is central to independence and financial capacity. Multiple brain regions and cognitive factors have been proposed to be involved in economic decision-making. The ability to make rational decisions is typically studied in older adults because this group is most likely to have difficulties with financial decisions (Agarwal et al., 2009) and make suboptimal economic choices (Agarwal et al., 2009). Indeed, it is often anecdotally reported that older adults are easily scammed and make poor decisions concerning financial matters.

Neuroeconomic research defines rational decision-making within the framework of economic utility maximization. This theory proposes that choices must satisfy the General Axiom of Revealed Preference (GARP), such that they are internally consistent and transitive. For example, if someone prefers chocolate to ice cream, and ice cream to lollipops, a rational person should always choose chocolate to lollipops. As such, consistency of

Received Feb. 1, 2018; revised March 8, 2018; accepted March 19, 2018

I thank Professor Skye McDonald, Dr. Jane Franklin, and Dr. Fiona Kumfor for providing feedback on the initial version of the manuscript.

The authors declare no competing financial interests.

Correspondence should be addressed to Dr. Travis A. Wearne, University

of New South Wales, School of Psychology, Mathews Building, Kensington, 2052 NSW, Australia. E-mail: t.wearne@unsw.edu.au.

DOI:10.1523/JNEUROSCI.0330-18.2018

Copyright $\odot 2018$ the authors $\quad 0270-6474 / 18 / 384059-03 \$ 15.00 / 0$ subjective value and choice is central to economic decisions and rationality. While the view of utility maximization has long been held within the economic field, the neural mechanisms underlying economic rationality and whether these mechanisms are intact in older adults, has not been explored fully.

To address this, Chung et al. (2017) recently examined experimentally derived estimates of GARP violations in 39 healthy older adults (65-92 years of age) using a behavioral paradigm routinely used in experimental economics. In this task, participants were presented with bundles comprising of different quantities of two real consumer goods (e.g., $4 \mathrm{Su}$ doku books and 2 crossword books or 5 Sudoku books and 1 crossword book) and asked to choose which bundle they preferred. Each trial consisted of 3-7 different combinations, and the participants were asked their preferences across 11 choice sets. The authors assessed the frequency and severity of GARP violations by determining whether participants were consistent in their choices when offered different combinations of goods across trials. The results revealed that $42.11 \%$ of their sample made two or more GARP violations. Importantly, the authors found that the frequency and severity of GARP violations did not correlate with age in their sample.

Given that the behavioral results suggest that there is no linear relationship between age and economic rationality, heterogeneity in rationality within older adults may reflect variability in brain structure. Therefore, the authors used whole-brain voxel-based morphometry to assess the relationship between economic rationality and gray matter integrity. More frequent and severe violations to GARP were correlated with gray matter reductions in the ventrolateral prefrontal cortex (VLPFC). The authors concluded that integrity of the VLPFC, rather than chronological age, is an important determinant of economic rationality in older adults.

To elucidate potential network contributions between the VLPFC and economic rationality, the authors then performed an analysis of the VLPFC and reward using Neurosynth, a meta-analytic neuroimaging database based on 11,406 fMRI studies from other authors. These findings demonstrated that the VLPFC tends to coactivate with frontoparietal regions, including the dorsolateral PFC and VMPFC prefrontal cortices, the striatum, and posterior parietal cortex. The authors concluded that, via this functional brain network, the VLPFC is involved in utility maximization and decisionmaking processes.

The study by Chung et al. (2017) provides insights into the neural substrates of economic rationality in older adults. The finding that the stability of utility maximization is contingent on the integrity of 
VLPFC rather than chronological age is significant, as it suggests that economic irrationality is not an inevitable phenomenon in older aging, but rather a result from neuroanatomical alterations. This corroborates research across healthy and clinical groups showing that neural changes, rather than chronological age per se, are important determinants of functional and cognitive outcomes (Rusinek et al., 2003).

An important question is the extent to which the results reported by Chung et al. (2017) generalize to the broader context of economic decision-making and behavior. Decision-making is multidimensional and incorporates elements of choice, probability, delay, and reward. Additionally, several economic researchers propose that GARP is a nonessential factor in economic behavior (Choi et al., 2014), and models of financial capacity propose that multiple cognitive faculties are necessary for economic decisions, including attention, memory, and reasoning (Marson, 2016). As such, while older adults may commit elevated GARP violations, cognitive reserve and situational factors could prevent the deleterious effect of economic irrationality from translating into real-world difficulties with financial decisions.

Because Chung et al. (2017) have only assessed GARP, examining the relationship between GARP and real-life economic behavior in older adults would provide important evidence to support the significance of their findings.

Although there are potential caveats in the significance of GARP violations in the broader context of economic decisionmaking, Chung et al. (2017) reported that GARP is associated with greater VLPFC integrity in older aging. An additional consideration, therefore, is how the VLPFC is involved in economic rationality and how it fits within the functional network of decision-making processes. Chung et al. (2017) proposed that the VLPFC maintains preference, limits distractibility, and detects available options.

In support of the author's interpretation, the VLPFC may maintain cognitive control and selective attention over competing choices, particularly for salient stimuli. The VLPFC has been shown to be coactive with numerous regions within both the central executive network (e.g., dorsolateral PFC and posterior parietal cortex) and the salience network (e.g., anterior insula and anterior cingulate cortex) (e.g., McTeague et al., 2017). The salience network, in particular, is re- cruited in response to changes in the environment that capture attention, with the anterior insula thought to respond transiently to subjective salient stimuli that is then sustained by the VLPFC (Menon and Uddin, 2010). The VLPFC may therefore maintain attention according to subjective salience and inhibit response tendencies that are incongruent to goal-directed tasks. Consequently, those with reduced integrity of the VLPFC may be more disorganized in their attentional and/or cognitive control, with GARP violations representing a failure to apply sequencing and cognitive loads appropriately (i.e., loss of attentional control over the task and making choices inconsistent with their preferences). To further support this view, the VLPFC has been implicated in attentional (Braver, 2012) and cognitive (McTeague et al., 2017) control, task switching (Braver et al., 2003), and sequencing of behavioral stimuli or actions (Shima et al., 2007).

An alternative, albeit not mutually exclusive interpretation, is that the VLPFC regulates strategic use of goal-directed behavior. Baxter et al. (2009) found a double dissociation between the VLPFC and the orbitofrontal cortex/VMPFC, such that lesions to the VLPFC impaired strategybased performance whereas localized lesions to the orbitofrontal cortex caused problems with value-based decisionmaking. Furthermore, age-related differences in problem-solving strategy among older adults are associated with reduced activity in the VLPFC (Hampshire et al., 2008). The VLPFC in economic rationality in older adults, therefore, may maintain a logical and consistent strategy based on higher-order information (e.g., categorical) from sensory stimuli, particularly when faced with multiple competing choices. In support of this, the VLPFC has been shown to enable retrieval of categorical information associated with visual stimuli (Bunge et al., 2003) and updates representations of stimulus-outcome probabilities based on the availability of options (Rudebeck et al., 2017).

There are dissociated roles of brain circuitry in decision-making processes, with the VMPFC important for relaying stimuli-associated value, the striatum for predictive and actual outcomes, and the posterior parietal cortex for integrating information (Kable and Glimcher, 2009). Therefore, determining the specific role of the VLPFC within this network is of importance. Future studies should implement lesion-model approaches in human samples to the VLPFC to elucidate the cognitive and motivational considerations of this region in utility maximization. A potential avenue would be dementia syndromes and acquired brain impairment, as these are concomitant with pathology specific to the frontal lobes and patients often have difficulties with financial decision-making (Sherod et al., 2009; Dreer et al., 2012). Given the limited range in the frequency of GARP violations in the study by Chung et al. (2017), representing greater variability of economic rationality by focusing on clinical samples would enable examination of additional brain structures, and cognitive faculties, that have been implicated in utility maximization, specifically with respect to the salience and decision-making networks. Additionally, the use of clinical samples would enable greater examination of the clinical significance of the VLPFC and GARP violations in mediating economic behavior.

In conclusion, the study by Chung et al. (2017) proposes that the VLPFC is an important brain region that contributes to economic rationality in older adults. The findings provide interesting avenues for research concerning how GARP violations could lead to financial difficulties, particularly for clinical samples prone to limited financial capacity, and enable further exploration of the role of the VLPFC in the neural architecture of economic decision-making processes.

\section{References}

Agarwal S, Driscoll JC, Gabaix X, Laibson D (2009) The age of reason: financial decisions over the life cycle and implications for regulation. Brookings Papers Econ Activity 2009: 51-117. CrossRef

Baxter MG, Gaffan D, Kyriazis DA, Mitchell AS (2009) Ventrolateral prefrontal cortex is required for performance of a strategy implementation task but not reinforcer devaluation effects in rhesus monkeys. Eur J Neurosci 29: 2049-2059. CrossRef Medline

Braver TS (2012) The variable nature of cognitive control: a dual-mechanisms framework. Trends Cogn Sci 16:106-113. CrossRef Medline

Braver TS, Reynolds JR, Donaldson DI (2003) Neural mechanisms of transient and sustained cognitive control during task switching. Neuron 39:713-726. CrossRef Medline

Bunge SA, Kahn I, Wallis JD, Miller EK, Wagner AD (2003) Neural circuits subserving the retrieval and maintenance of abstract rules. J Neurophysiol 90:3419-3428. CrossRef Medline

Choi S, Kariv S, Müller W, Silverman D (2014) Who is (more) rational? Am Econ Rev 104: 1518-1550. CrossRef

Chung HK, Tymula A, Glimcher P (2017) The reduction of ventrolateral prefrontal cortex 
gray matter volume correlates with loss of economic rationality in aging. J Neurosci 37: 12068-12077. CrossRef Medline

Dreer LE, Devivo MJ, Novack TA, Marson DC (2012) Financial capacity following traumatic brain injury: a six-month longitudinal study. Rehabil Psychol 57:5-12. CrossRef Medline

Hampshire A, Gruszka A, Fallon SJ, Owen AM (2008) Inefficiency in self-organized attentional switching in the normal aging population is associated with decreased activity in the ventrolateral prefrontal cortex. J Cogn Neurosci 20:1670-1686. CrossRef Medline

Kable JW, Glimcher PW (2009) The neurobiology of decision: consensus and controversy. Neuron 63:733-745. CrossRef Medline

Marson D (2016) Conceptual models and guide- lines for clinical assessment of financial capacity. Arch Clin Neuropsychol 31:541-553. CrossRef Medline

McTeague LM, Huemer J, Carreon DM, Jiang Y, Eickhoff SB, Etkin A (2017) Identification of common neural circuit disruptions in cognitive control across psychiatric disorders. J Psychiatry 174:676-685. CrossRef Medline

Menon V, Uddin LQ (2010) Saliency, switching, attention and control: a network model of insula function. Brain Struct Funct 214:655667. CrossRef Medline

Rudebeck PH, Saunders RC, Lundgren DA, Murray EA (2017) Specialized representations of value in the orbital and ventrolateral prefrontal cortex: desirability versus availability of outcomes. Neuron 95:1208-1220.e5. CrossRef Medline
Rusinek H, De Santi S, Frid D, Tsui WH, Tarshish CY, Convit A, de Leon MJ (2003) Regional brain atrophy rate predicts future cognitive decline: 6-year longitudinal MR imaging study of normal aging. Radiology 229:691696. CrossRef Medline

Sherod MG, Griffith HR, Copeland J, Belue K, Krzywanski S, Zamrini EY, Powers RE (2009) Neurocognitive predictors of financial capacity across the dementia spectrum: normal aging, mild cognitive impairment, and Alzheimer's disease. J Int Neuropsychol Soc 15:258 267. CrossRef Medline

Shima K, Isoda M, Mushiake H, Tanji J (2007) Categorization of behavioural sequences in the prefrontal cortex. Nature 445:315-318. CrossRef Medline 